\title{
Survival of Isolates of the US-22, US-23, and US-24 Clonal Lineages of Phytophthora infestans by Asexual Means in Tomato Seed at Cold Temperatures
}

\author{
Kenneth E. Frost, Anna C. Seidl Johnson, and Amanda J. Gevens, Department of Plant Pathology, University of Wisconsin-Madison 53706
}

\begin{abstract}
Frost, K. E., Seidl Johnson, A. C., and Gevens, A. J. 2016. Survival of isolates of the US-22, US-23, and US-24 clonal lineages of Phytophthora infestans by asexual means in tomato seed at cold temperatures. Plant Dis. 100:180-187.

Survival of Phytophthora infestans, causal agent of potato and tomato late blight, is thought to be negligible when exposed to freezing conditions typical of a Wisconsin winter. However, the persistence of relatively new $P$. infestans clonal lineages US-22, US-23, and US-24 within a production region during 2010 to 2014 warranted further investigation. We used tomato seed as a culture medium to determine the survival of $P$. infestans isolates representing the three lineages under temperatures of $18,4,0,-3$, and $-5^{\circ} \mathrm{C}$ for 11 time points ( 1 to 112 days postincubation). Survival varied interactively with temperature, duration of time at a temperature, and clonal lineage of the P. infestans isolate. US-22, -23 , and -24 isolates survived for 112 days at 18 and $4^{\circ} \mathrm{C}, 84$ days at $0^{\circ} \mathrm{C}$, and 14 days at $-3^{\circ} \mathrm{C}$. US-23 survived longer at -3 and $-5^{\circ} \mathrm{C}$ than did US-22 or US-24. The vigor of US-22 and US-24 isolates decreased with increasing exposure to cold temperatures, a trend that was not observed for the US-23 isolate. By calculating the length of time needed

to kill the lineage isolates on infested tomato seed at five temperatures, we predicted that $P$. infestans would survive in $5 \%$ of tomato seed for 99,25 , and 16 days at $0,-3$, and $-5^{\circ} \mathrm{C}$, respectively. We further applied a degree-day model to our empirical data to describe $P$. infestans survival as a function of cooling degree-day accumulations using archived soil temperatures at $5-$ and $10-\mathrm{cm}$ depths at four Wisconsin locations over 27 years. The model indicated that survival of P. infestans in 5\% of infested tomato seed would occur at 35 and $39 \%$ of the location-year combinations at 5- and $10-\mathrm{cm}$ soil depths, respectively. Together, these data suggested that $P$. infestans has the potential to survive over the winter season by asexual means in infested tomato seed in Wisconsin and other Northern latitudes. Our cooling degree-day model for late blight in the tomato production system offers a tool for anticipating and mitigating disease based on integrated pest management concepts previously utilized for insects.
\end{abstract}

Phytophthora infestans (Mont.) de Bary, the causal agent of late blight, is one of the most destructive pathogens of potato (Solanum tuberosum L.) and tomato (S. lycopersicum L.) worldwide. The financial cost of field and storage losses to late blight in potato alone has been significant despite decades of enhanced pathogen understanding and management progress (Fry 2007; Guenthner et al. 2001; Wustman 2007). Survival of $P$. infestans at freezing temperatures is believed to be limited because $P$. infestans is, functionally, an obligate parasite in its asexual state (Fry 2008; Stevenson et al. 2001); when infected plant tissues are killed with a winter freeze, the pathogen cannot survive because sexual reproduction and development of resilient oospores are not known to occur in the northern United States (Gavino et al. 2000; Goodwin et al. 1998; Kalischuk et al. 2012; Ristaino 2010). Although this pathogen is thought to be eliminated from northern regions each winter, when cold temperatures destroy living plant material in open field settings, any plant tissues that may be protected from extreme cold conditions can serve as potential pathogen reservoirs.

Overwinter survival of asexually reproducing $P$. infestans has been investigated in some regions and, in potato production systems, overwinter survival in cull piles has been demonstrated (Bonde and Schultz 1943; Kirk 2003a,b). Even in regions where winter air temperatures fall below $0^{\circ} \mathrm{C}$, tubers located in the center of a cull pile can be insulated and remain above freezing (Kirk 2003a). If those tubers are infected with $P$. infestans, they have the potential to produce infected sprouts the following season (Bonde and Schultz 1943; Gigot et al. 2009; Johnson and Cummings 2013; Lambert et al. 1998; Zwankhuizen et al. 1998). Infected tubers can also remain in production fields postharvest. If deeply buried in soil or under heavy snow cover,

Corresponding author: A. J. Gevens; E-mail: gevens@wisc.edu

Accepted for publication 26 June 2015.

http://dx.doi.org/10.1094/PDIS-04-15-0462-RE

(C) 2016 The American Phytopathological Society infected potato can be insulated from ambient air temperatures below $0^{\circ} \mathrm{C}$, enabling the survival of the pathogen through the winter (Kirk 2003a,b; Kirk et al. 2001). In tomato production systems located in northern regions of the United States, $P$. infestans survival in fruit and seed is assumed to be reduced due to freezing winter temperatures but surviving over the winter in compost piles is thought to occur occasionally (Gevens et al. 2010). In California, where temperatures do not regularly drop below $0^{\circ} \mathrm{C}$, infected seedlings have been observed emerging from buried tomato fruit a few weeks after the crop has been harvested (Vartanian and Endo 1985a). Other research has shown that wet or freshly extracted tomato seed infested with $P$. infestans and exposed to temperatures as low as $10^{\circ} \mathrm{C}$ can give rise to infected seedlings (Vartanian and Endo 1985b) but the survival of $P$. infestans in tomato seed below $10^{\circ} \mathrm{C}$ was not investigated.

A few studies have explored the ability of $P$. infestans, in an asexual life stage, to survive cold or below-freezing temperatures. In 1926, deBruyn (1926) tested the survival of $P$. infestans in various substrata and concluded that the pathogen could survive in manure for 5 days with temperatures as low as $-25^{\circ} \mathrm{C}$; however, the possibility that oospores formed in the cultures could not be eliminated. More recently, Kirk (2003b) tested survival of mycelia of four clonal lineages (CL) of $P$. infestans in culture media and found survival for up to 3 days at $-3^{\circ} \mathrm{C}$; however, the pathogen did not survive for more than $24 \mathrm{~h}$ at $-5^{\circ} \mathrm{C}$. Dandurand et al. (2006) demonstrated survival of $P$. infestans at low temperatures on natural substrata by noting that $P$. infestans remained viable in berries of nightshade weeds that were frozen for $48 \mathrm{~h}$ at $-15^{\circ} \mathrm{C}$. However, the potential for $P$. infestans to survive over the winter in production systems in northern latitudes still is not well understood because these experiments were short in duration when compared with the length of winters (or cold temperatures) typical of northern latitudes.

The US-22 CL of $P$. infestans was newly identified in the United States in 2009 when it caused widespread late blight, primarily on tomato, across the Eastern and Midwestern United States (Danies et al. 2013; Hu et al. 2012; Ristaino 2010; Seidl and Gevens 2013). In Wisconsin, tomato late blight caused by the US-22 lineage was widespread 
in 2009 and occurred again in 2010 (Seidl and Gevens 2013), raising questions about its ability to survive over the winter in production systems. Also in 2010, two new CL, US-23 and US-24, were identified in Wisconsin and became widespread in the state and across the United States (Gevens and Seidl 2013a,b). The objective of this study was to investigate the potential for surviving over the winter of asexually reproducing US-22, US-23, and US-24 CL of $P$. infestans. To do this, the survival of these CL was quantified by subjecting $P$. infestans-infected tomato seed to long-term freezing conditions. Additionally, vigor of the surviving "individuals" subjected to different durations of freezing conditions was assessed. A cooling degree-day (CDD) model was developed to predict $P$. infestans survival on tomato seed, and soil temperature data then were used to estimate the potential for $P$. infestans to survive over the winter in the Wisconsin environment.

\section{Materials and Methods}

$P$. infestans isolates. All $P$. infestans isolates were collected from symptomatic plant tissues from Wisconsin in 2009 or 2010, and have been previously described (Seidl and Gevens 2013). A single isolate from each CL was used for the survival assays. Although of interest, we did not include comparison of one of the older lineages because isolates that have been maintained in long-term storage can lose virulence over time (Goth 1981; Hodgson and Grainger 1964; Thurston 1957). The US-22 isolate, Pi7-09a, is an A2 mating type and was collected from infected tomato fruit tissue. The US-23 isolate, Pi16-10a, is an A1 mating type and was isolated from infected tomato leaf tissue. The US-24 isolate, Pi21-10a, is an A2 mating type and was isolated from infected potato leaf tissue. All $P$. infestans cultures were derived from single zoospore isolations, and oospore production in single-isolate cultures was never observed. Isolates used for the survival experiment were transferred minimally in culture after isolation to maintain the original characteristics of the isolates (Goth 1981; Hodgson and Grainger 1964; Thurston 1957). For long-term storage, isolates were maintained in hemp seed (Lamour and Hausbeck 2001) in the Potato and Vegetable Pathology Laboratory at the University of Wisconsin-Madison. Single representative isolates of each $P$. infestans CL used in previous studies indicated that recently identified lineages showed low variation in biological characteristics (Danies et al. 2013; Mizubuti and Fry 1998). For the purpose of simplifying the results and discussion of our data pertaining to each isolate of US-22, US-23, and US-24, the representative isolate is often referred to as "the CL."

$\boldsymbol{P}$. infestans survival and vigor assays. Commercially available nonfungicide-treated tomato seed ('Brandywine Red'; Reimers Seeds, Saint Leonard, MD) were used for the survival assays. Three tomato seeds were added to each of $1101.5-\mathrm{ml}$ microcentrifuge tubes and sterilized in an autoclave. Sterile distilled water $(0.75 \mathrm{ml})$ and one 7-mm-diameter plug of mycelia or sporangia from a 3-weekold $P$. infestans isolate actively growing on rye A media (Caten and Jinks 1968) were added to each tube. All tubes were sealed and incubated at $18^{\circ} \mathrm{C}$ for 4 weeks to allow for colonization of the tomato seed. Autoclaved tomato seed $(n=3)$ receiving sterile distilled water and no pathogen inoculation were included as an experimental control. The agar plug was removed from each tube after incubation. Tubes were resealed and randomly placed in each of five 80 -well plastic microcentrifuge tube racks. The entire procedure was repeated for each of the three selected $P$. infestans isolates. Each microcentrifuge tube rack contained 66 tubes, 22 tubes per isolate, and one rack was placed at each temperature: $-5,-3,0,4$, and $18^{\circ} \mathrm{C}$ (Environmental Chamber and Refrigerator/Freezer, Hotpack Corp., Philadelphia). Incubator temperatures fluctuated no more than $0.5^{\circ} \mathrm{C}$ from the desired temperatures throughout the duration of experiments, as determined by temperature loggers (Spectrum Technologies, Aurora, IL; data not shown). Relative humidity was ambient at approximately 55\% in the incubators (data not shown).

Survival of each isolate of $P$. infestans was tested at 1, 2, 3, 5, 7, $14,21,28,56,84$, and 112 days after exposure to each temperature treatment. For the time points at or before 28 days, the sampling was performed at exactly the time specified, $\pm 5 \mathrm{~min}$. Later time points were exact \pm 2 h. For each of the 11 time points, two tubes of each isolate at each temperature were randomly selected and removed from the incubators. Within $2 \mathrm{~h}$ of removal, the six seeds from the two tubes were placed on rye A medium in 9-cm petri plates and incubated at $20^{\circ} \mathrm{C}$ with a 12 -h photoperiod. Individual seeds plated on media were evaluated using a dissecting microscope at 7, 14, and 21 days after plating. Survival of $P$. infestans was assessed as 0 (no growth) or 1 (visible growth). The pathogen was identified based on morphological features of $P$. infestans (Waterhouse 1963).

The amount of $P$. infestans growth from each seed was then quantified using a vigor index of 0 to 4 , where $0=$ no $P$. infestans growth, $1=$ less than 10 short $(<0.50 \mathrm{~mm})$ mycelial strands, $2=$ more than 10 longer $(>0.50 \mathrm{~mm})$ mycelial strands but not a wide-spreading colony, $3=$ a wide-spreading colony, and $4=$ a wide-spreading colony with a thick, profuse layer of mycelia or sporangia. The experiment was replicated twice in its entirety, and a third experimental replication was ended after the day-56 sampling.

Data analysis. The data from these experiments were examined in three different ways. First, a generalized linear modeling approach based on binomial regression (logit-link) was used to model $P$. infestans survival (i.e., alive or dead) as a function of CL and duration of time (Time) that a seed remained at an experimental temperature (Temp) prior to sampling (Venables and Ripley 2002). Initially, a full model, with Temp and CL as categorical covariates, Time as a continuous covariate, and all interaction terms among covariates (i.e., Time-CL, Time-Temp, CL-Temp, and Time-CL-Temp) was fit to the data. Experimental replication was included in the analysis as a blocking factor and allowed to interact with all model terms. Analysis of deviance was used to adjudicate the significance of the model terms. Because there were several significant interaction terms in the initial regression model, the full model was further subdivided to examine the importance of isolate and time within a temperature treatment and submodels then were evaluated separately. The submodels were used to calculate the length of time in days (ED), averaged over experimental replicates, needed to kill 50,75, and 95\% of US-22, US-23, and US-24 CL isolates of $P$. infestans on infested tomato seed at five temperatures.

The second analysis of these data modeled $P$. infestans survival as a function of simple CDD, calculated using a base temperature of $1{ }^{\circ} \mathrm{C}$ $\left(\mathrm{T}_{\mathrm{b}}\right)$ for each temperature and exposure time treatment (Campbell and Norman 1998). CDD below the base temperature were calculated as $C D D=T_{b}-T_{x}$, where $T_{x}$ was the growth chamber temperature. Once CDD were obtained for each day, they were summed cumulatively for the duration of time that each treatment was maintained prior to sampling. The data from each experimental replication were aggregated for a CL and CDD estimate, resulting in the number of surviving and number of dead $P$. infestans samples for each CL-CDD combination. Logistic regression was used to model the survival of $P$. infestans as a function of log-transformed CDD calculated using a base temperature of $1^{\circ} \mathrm{C}$. The logistic regression model can be represented as $\log _{\mathrm{e}}\left(\mathrm{Y}_{\mathrm{i}} / 1-\mathrm{Y}_{\mathrm{i}}\right)=\mathrm{B}_{0}+\mathrm{B}_{1} \mathrm{X}_{\mathrm{i}}$, where the odds of survival are represented by $\mathrm{Y}_{\mathrm{i}} / 1-\mathrm{Y}_{\mathrm{i}}, \mathrm{X}_{\mathrm{i}}$ is the log-transformed $\mathrm{CDD}\left(\log _{\mathrm{e}}\right)$, and $\mathrm{B}_{0}$ and $\mathrm{B}_{1}$ are regression coefficients (the intercept and slope, respectively) (Kutner et al. 2004). Again, experimental replication was considered a blocking factor and allowed to interact with all model terms. Analysis of deviance was used to adjudicate the significance of the model terms. The average CDD necessary to have the probability of survival $(\mathrm{Y})$ be $0.50,0.75$ and 0.95 was estimated by substituting $0.50,0.75$, or 0.95 for $\mathrm{Y}$ in the fitted regression equation, and solving for $\mathrm{X}$, the CDD (log-transformed) (Kutner et al. 2004). These estimates were used to calculate the average number of days at $0,-3$, and $-6^{\circ} \mathrm{C}$ necessary to kill 50,75 , and $95 \%$ of $P$. infestans in the infested tomato seed. All logistic regression models were fit in R 3.0.2 (R Core Team 2014) using the glm function (binomial, logit-link). Parameter estimates, $\chi^{2}$ test statistics, and ED estimates ( \pm standard error [SE]) were extracted using the summary, anova, and dose.p functions in the MASS package (Venables and Ribley 2002).

Finally, for the third analysis, the three vigor ratings (taken at 7, 14, and 21 days after placing the seed on media) were summed for each of the exposure times and each CL-Temp combination for each 
"individual" that survived. The resulting value was divided by 12 , yielding a vigor index that was scaled to fall between 0 (no growth) and 1 (maximal growth) for each treatment combination. $\mathrm{CDD}\left(\mathrm{T}_{\mathrm{b}}=\right.$ $19^{\circ} \mathrm{C}$ ) were calculated for each exposure Time-Temp combination and experimental replication (three total), as described above (Campbell and Norman 1998). The vigor index was then modeled as a linear function of CDD (log), CL, and the interaction term CDD (log)-CL, with experimental replication as a blocking factor and allowed to interact with all model terms. Because the interaction term CDD ( $\log$ )-CL was significant, the regression model was subdivided to examine the relationship between vigor and CDD $(\log )$ for each CL separately. All linear regression models were fit in $\mathrm{R}$ (version 3.0.2) using the $l m$ function and parameter estimates, and test statistics were extracted using the summary and anova functions ( $\mathrm{R}$ Core Team 2014).

Environmental variability of $\boldsymbol{P}$. infestans survival. To examine the potential for $P$. infestans to survive overwinter in Wisconsin, soil temperature data at two depths, 5 and $10 \mathrm{~cm}$, were assembled from four locations. In total, 10, 27, 27, and 22 years of soil temperature data were obtained for Antigo (1988 to 1997), Arlington (1987 to 2013), Hancock (1987 to 2013), and Spring Green (1989 to 1997 and 2001 to 2011), respectively. These soil temperature data were downloaded from the University of Wisconsin Soil Science website (http://agwx.soils.wisc.edu/uwex_agwx/awon). CDD $\left(\mathrm{T}_{\mathrm{b}}=1^{\circ} \mathrm{C}\right)$ were calculated using soil temperature data at 5 and $10 \mathrm{~cm}$ below the soil surface and daily values were summed for the winter (15 October through 1 May) at each location. The degree-day model (described above) was then used to determine the probability that an individual from a $P$. infestans $C L$ would have survived the cold temperatures of each location's winter. Data were then summarized to reflect the percentage of years in which at least 5, 25, and 50\% of $P$. infestans individuals could have survived over the winter in a population of $P$. infestans-infected tomato seed at each location and soil depth.

\section{Results}

$P$. infestans survival. No $P$. infestans or other microorganisms grew from the noninoculated, autoclaved control tomato seed. Survival of $P$. infestans was modeled as a function of Temp, Time, and the CL of the assayed isolate. When a full model including all of the interaction terms among the covariates was fit to the data, an analysis of deviance identified several significant interaction terms, including the Time-CL-Temp term (Table 1). This finding suggested that survival varied interactively with Temp, Time, and CL of the $P$. infestans isolate.

To better understand these survival data, the full model was subdivided by Temp and individual models of survival as a function of Time, CL, and the Time-CL interaction term were fit (analysis of deviance tables for separate model fits, not shown). Survival of isolates of the three $\mathrm{CL}$ at $18^{\circ} \mathrm{C}$ was high, with $97 \%$ of samples surviving at day 112 of the experiment. In fact, the binomial model predicted it would take 304 and 268 days to kill $95 \%$ of each $P$. infestans isolate representing US-22 and US-23, respectively, in the infested tomato seed (Table 2). The high survival rate of $P$. infestans at this temperature caused difficulty in estimating some parameters for the binomial regression model, and survival times for the isolate representing US-24 could not be estimated. At $4^{\circ} \mathrm{C}$, survival of $P$. infestans also was high,

Table 2. Average length of time in days (standard error) and proportion of Phytophthora infestans infested seed expected to contain live $P$. infestans for the US-22, US-23, and US-24 isolates at five temperatures (Temp) based on binomial regression modeling

\begin{tabular}{lcccc}
\hline & & \multicolumn{3}{c}{ Isolate $^{\mathbf{a}}$} \\
\cline { 3 - 5 } Temp $\left({ }^{\circ} \mathbf{C}\right)$ & Pr $(\text { alive })^{\mathbf{b}}$ & US-22 & US-23 & US-24 \\
\hline 18 & 0.50 & $212(62)$ & $176(44)$ & $\mathrm{NE}$ \\
& 0.25 & $246(73)$ & $210(56)$ & $\mathrm{NE}$ \\
& 0.05 & $304(94)$ & $268(78)$ & $\mathrm{NE}$ \\
4 & 0.50 & $90(6)$ & $197(89)$ & $112(14)$ \\
& 0.25 & $105(7)$ & $228(111)$ & $143(19)$ \\
& 0.05 & $130(11)$ & $279(149)$ & $196(29)$ \\
0 & 0.50 & $44(4)$ & $34(3)$ & $35(4)$ \\
& 0.25 & $59(5)$ & $49(4)$ & $51(4)$ \\
& 0.05 & $85(7)$ & $75(6)$ & $77(6)$ \\
-3 & 0.50 & $4(1)$ & $4(1)$ & $4(0)$ \\
& 0.25 & $6(1)$ & $9(1)$ & $5(1)$ \\
& 0.05 & $10(1)$ & $17(3)$ & $8(1)$ \\
-5 & 0.50 & $3(0)$ & $1(0)$ & $2(0)$ \\
& 0.25 & $4(0)$ & $3(0)$ & $3(0)$ \\
& 0.05 & $6(1)$ & $6(1)$ & $4(1)$ \\
\hline
\end{tabular}

a $\mathrm{NE}=$ not estimated.

b Proportion $(0.50,0.25$, or 0.05$)$ of $P$. infestans infested tomato seed expected to contain living $P$. infestans.

Table 1. Analysis of deviance table for binomial generalized linear model describing the effect of temperature and duration of exposure to a temperature on the survival of Phytophthora infestans in infested tomato seed

\begin{tabular}{|c|c|c|c|c|c|}
\hline Model terms $^{\mathbf{a}}$ & DF residual ${ }^{b}$ & Residual deviance $^{c}$ & $\mathbf{D F}^{\mathrm{d}}$ & Deviance $^{\mathrm{e}}$ & $\operatorname{Pr}(>\chi)^{f}$ \\
\hline Time & 448 & 2683 & 1 & 248 & $<0.0001$ \\
\hline $\mathrm{CL}$ & 446 & 2682 & 2 & 1.0 & 0.5944 \\
\hline Temp & 442 & 748 & 4 & 1934 & $<0.0001$ \\
\hline Exp & 440 & 736 & 2 & 12 & 0.0028 \\
\hline Time $\times C L$ & 438 & 714 & 2 & 22 & $<0.0001$ \\
\hline Time $\times$ Temp & 434 & 459 & 4 & 256 & $<0.0001$ \\
\hline CL $\times$ Temp & 426 & 434 & 8 & 24 & 0.0019 \\
\hline Time $\times \operatorname{Exp}$ & 424 & 423 & 2 & 11 & 0.0034 \\
\hline$C L \times \operatorname{Exp}$ & 420 & 408 & 4 & 15 & 0.0044 \\
\hline Temp $\times \operatorname{Exp}$ & 412 & 383 & 8 & 25 & 0.0017 \\
\hline Time $\times$ CL $\times$ Temp & 404 & 360 & 8 & 23 & 0.0028 \\
\hline Time $\times$ CL $\times \operatorname{Exp}$ & 400 & 352 & 4 & 8 & 0.0919 \\
\hline Time $\times$ Temp $\times$ Exp & 392 & 329 & 8 & 23 & 0.0038 \\
\hline CL $\times$ Temp $\times$ Exp & 376 & 300 & 16 & 30 & 0.0206 \\
\hline Time $\times$ CL $\times$ Temp $\times \operatorname{Exp}$ & 360 & 290 & 16 & 9 & 0.9108 \\
\hline
\end{tabular}

a Time refers to the number of days the treatment was exposed to a temperature, CL refers to clonal lineage of $P$. infestans isolates, Temp refers to temperature $\left({ }^{\circ} \mathrm{C}\right)$, and Exp refers to experimental replication.

$\mathrm{b}$ Residual degrees of freedom.

${ }^{\mathrm{c}}$ Residual deviance of the model; residual deviance of the null model was 2,932 on 449 degrees of freedom; Akaike Information Criterion of full model was 675.7 .

d Degrees of freedom for model terms.

e Reduction in deviance by the sequential inclusion of terms in the model.

${ }^{\mathrm{f}} P$ value, based on a $\chi^{2}$ test, associated with the reduction in deviance by inclusion of terms in the model. 


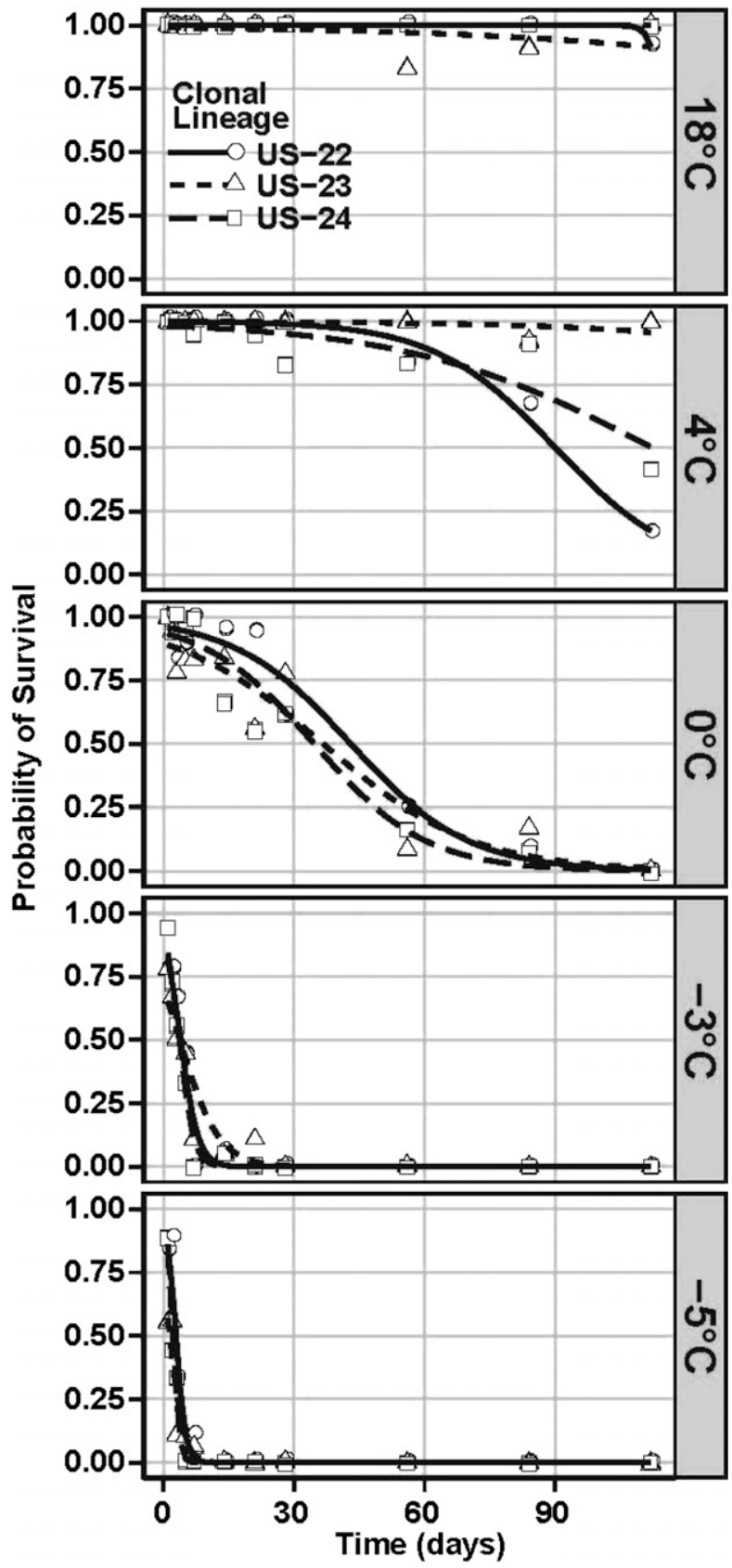

Fig. 1. Survival of the US-22, US-23, and US-24 isolates of Phytophthora infestans in tomato seed estimated at five temperatures for 112 days. Each symbol represents the mean survival of 18 seeds ( 6 seeds per replication, three experimental replications). with 53\% of samples surviving after 112 days. However, the survival of $P$. infestans varied interactively depending on the CL of the isolate and the Time; the regression slopes varied by CL (Fig. 1, $\chi^{2}$ : Dev. = $7.6, \mathrm{DF}=2, P=0.02225$ ). For example, all samples of the isolate representing US-23 survived 112 days at $4^{\circ} \mathrm{C}$ (Fig. 1). However, for the two isolates representing the US-22 and US-24 CL, survival at $4^{\circ} \mathrm{C}$ started to decrease after 45 days, with only 17 and $42 \%$ of samples, respectively, surviving after 112 days. The binomial model for $4{ }^{\circ} \mathrm{C}$ predicted it would take 130, 279, and 196 days to kill $95 \%$ of the US-22, US-23, and US-24 CL isolates, respectively, in the infested tomato seed (Table 2).

At $0^{\circ} \mathrm{C}$, survival of $P$. infestans was documented until day 84 of the experiment but no survival of $P$. infestans was documented at day 112 of the experiment (Fig. 1). Additionally, at $0^{\circ} \mathrm{C}$, the regression slopes did not vary among the three isolates. To kill $95 \%$ of the US-22, US-23, and US-24 isolates infecting the tomato seed at $0^{\circ} \mathrm{C}$ would take 85,75 , and 77 days, respectively (Table 2).

Survival of $P$. infestans at $-3^{\circ} \mathrm{C}$ was documented until day 21 of the experiment but no survival was documented after day 21 . However, again, the survival of $P$. infestans varied interactively depending on the CL of the isolate and the Time (Fig. $1, \chi^{2}$ : Dev. $=13.9$, $\mathrm{DF}=2, P=0.0009$ ). Only $5 \%$ of each US-22, US-23, and US-24 CL isolate in infested tomato seed would survive for 10,17 , and 8 days, respectively, at $-3^{\circ} \mathrm{C}$ (Table 2).

At $-5^{\circ} \mathrm{C}$, survival was low, and documented until day 7 of the experiment. The isolate representing US-24 survived the shortest time, less than 5 days, and survival of the US-22 and US-23 isolates was documented at 7 days but not at 14 days. The binomial regression model predicted that $P$. infestans would not survive in $95 \%$ of the infected tomato seed for longer than 6 days at $-5^{\circ} \mathrm{C}$.

Degree-day model of $\boldsymbol{P}$. infestans survival. The survival of $P$. infestans decreased as a function of CDD which, when incorporated into the model, accounted for $82 \%$ of the residual deviance. Other model terms accounted for an additional 3\% of the residual deviance, and these model terms were primarily associated with the experimental replication. Similarly, the slopes of the regression model varied among CL but the variation was always associated with experimental replication (Table 3; Fig. 2). The variation associated with experiment was considered to be random variation and the regression model was reduced to provide an average slope and intercept that describes all isolates (Fig. 2 ). This model had an intercept of 4.20 and a slope of -1.53 on the scale of the linear predictor (Fig. 2; average $\mathrm{B}_{0}$ : estimate $=4.20, \mathrm{SE}=0.17$, $z=24.7, P<0.001 ;$ average $\mathrm{B}_{1}$ : estimate $=-1.53, \mathrm{SE}=0.06, z=$ $-26.2, P<0.001)$. The CDD $\left(\log _{\mathrm{e}}\right)$ that would allow survival of 50 , 25 , or $5 \%$ of $P$. infestans individuals in a population of $P$. infestansinfected tomato seed was estimated to be $2.75( \pm 0.04), 3.47( \pm 0.05)$, and $4.68( \pm 0.09)$, respectively (Fig. 2). Thus, $5 \%$ of $P$. infestans individuals in a population of $P$. infestans-infected tomato seed would be expected to survive for approximately 108,27 , and 18 days at $0,-3$, and $-5^{\circ} \mathrm{C}$, respectively (Table 4 ). These estimates were consistent with the previous estimates of survival time at those temperatures (Tables 2 and 4).

Table 3. Analysis of deviance table for binomial generalized linear model describing the effect of the duration of cold temperature exposure, expressed as cooling degree-days (CDD), on the survival of Phytophthora infestans in infested tomato seed

\begin{tabular}{|c|c|c|c|c|c|}
\hline Model terms ${ }^{\mathbf{a}}$ & DF residual ${ }^{b}$ & Residual deviance $^{c}$ & DF $^{\mathbf{d}}$ & Deviance $^{\mathrm{e}}$ & $\operatorname{Pr}(>\chi)^{f}$ \\
\hline $\mathrm{CL}$ & 225 & 2,633 & 2 & 1 & 0.6239 \\
\hline $\log (\mathrm{CDD}+1)$ & 224 & 473 & 1 & 2,161 & $<0.0001$ \\
\hline Exp & 222 & 447 & 2 & 26 & $<0.0001$ \\
\hline$C L \times \log (C D D+1)$ & 220 & 444 & 2 & 3 & 0.2684 \\
\hline$C L \times \operatorname{Exp}$ & 216 & 433 & 4 & 11 & 0.0230 \\
\hline $\log (C D D+1) \times \operatorname{Exp}$ & 214 & 426 & 2 & 7 & 0.0373 \\
\hline$C L \times \log (C D D+1) \times \operatorname{Exp}$ & 210 & 399 & 4 & 27 & $<0.0001$ \\
\hline
\end{tabular}

${ }^{\text {a }} \mathrm{CL}$ refers to isolates of $P$. infestans clonal lineage and Exp refers to experimental replication.

$\mathrm{b}$ Residual degrees of freedom.

${ }^{c}$ Residual deviance of the model; residual deviance of the null model was 2634 on 227 degrees of freedom; Akaike Information Criterion of full model was 675.7.

${ }^{\mathrm{d}}$ Degrees of freedom for model terms.

e Reduction in deviance by the sequential inclusion of terms in the model.

${ }^{\mathrm{f}} P$ value, based on a $\chi^{2}$ test, associated with the reduction in deviance by inclusion of terms in the model. 
$P$. infestans vigor index. The vigor of the surviving $P$. infestans individuals was modeled as a function of cold-exposure quantified as CDD $(\log )$ calculated using a base temperature of $19^{\circ} \mathrm{C}$. The slope of this relationship was dependent on the CL of the P. infestans isolate as determined by analysis of variance (Table 5). For this reason, individual simple linear regressions were performed on the data parsed by clonal linage (Fig. 3). The vigor of isolates belonging to the US-22 and US-24 CL decreased with increasing exposure to cold temperatures. For the isolate representing the US-23 CL, a significant response to increasing cold exposure was not observed.

Soil survival of $\boldsymbol{P}$. infestans. In Wisconsin, the magnitude of CDD calculated for soil temperatures measured at 5 - and $10-\mathrm{cm}$ soil depths was variable among years and locations (Table 6). Over all years for which data were acquired, the average values of winter-accumulated CDD were variable among locations $(F=3.18$, DF $=3,164, P=$ 0.0256 ) but did not vary significantly due to soil depth although, numerically, CDD values at 10-cm depths were lower when compared with those at $5-\mathrm{cm}$ soil depths (Table 7). Based on the CDD model

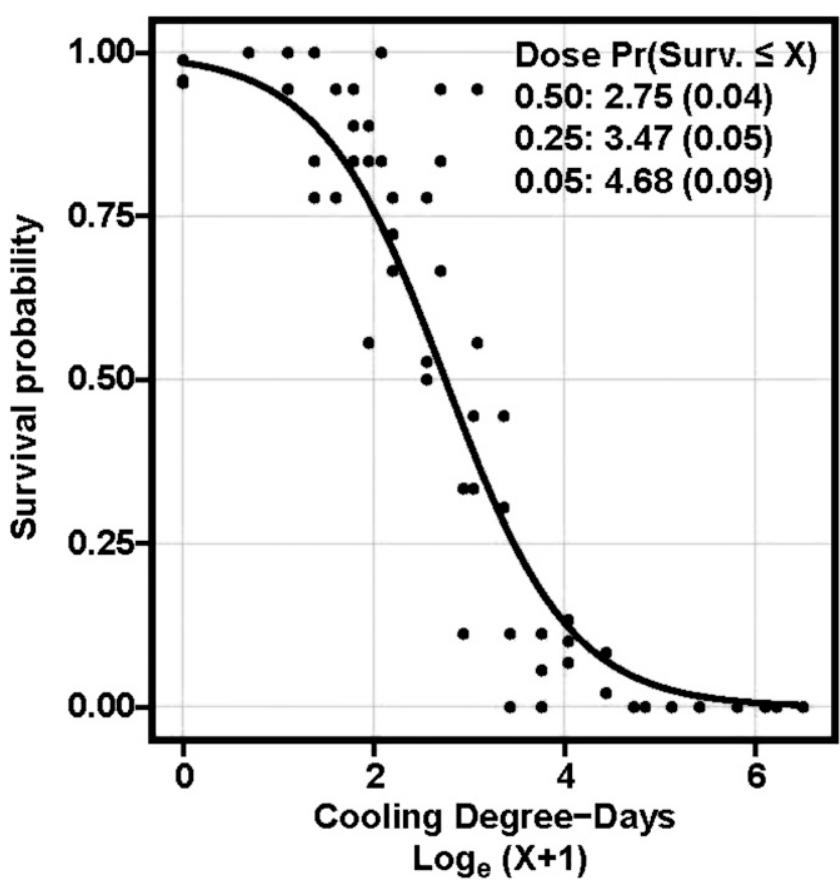

Fig. 2. Survival of the US-22, US-23, and US-24 isolates of Phytophthora infestans in infested tomato seed as a function of cooling degree-days (log). A base temperature of $1^{\circ} \mathrm{C}$ was used to calculate simple degree-days and all data for a clonal lineage were aggregated to degree-day values. The solid black line represents the average best fit line for all isolates, ignoring variation due to experimental replication. (described above) and soil temperatures at a depth of $5 \mathrm{~cm}, 5,25$, and $50 \%$ of $P$. infestans individuals in the population of $P$. infestansinfected seed would have survived at, on average, 34, 14, and $14 \%$ of the location-year combinations, respectively. Using soil temperatures at a depth of $10 \mathrm{~cm}$, the survival of $P$. infestans at 5, 25, and $50 \% P$. infestans individuals in the population of $P$. infestansinfected seed would increase slightly and occur at 39, 18, and $14 \%$, respectively, of the location-year combinations examined.

\section{Discussion}

Survival of $P$. infestans by asexual means at low temperatures has been studied previously in culture media assays outside of host tissues (Kirk 2003b; Mizubuti and Fry 1998), and on nightshade berries (Dandurand et al. 2006) for relatively short experimental durations, but has not been extensively explored in seed for longer durations. In this study, isolates representing the US-22, US-23, and US-24 CL of $P$. infestans recently identified and associated with tomato late blight epidemics were documented to survive on tomato seed for 79 days at $0^{\circ} \mathrm{C}, 12$ days at $-3^{\circ} \mathrm{C}$, and 5 days at $-5^{\circ} \mathrm{C}$. When these data were described as a function of CDD, our model predicted that an accumulation of $108 \mathrm{CDD}\left(\mathrm{T}_{\mathrm{b}}=1{ }^{\circ} \mathrm{C}\right)$ would result in $5 \%$ survival of $P$. infestans. Additionally, CDD accumulations calculated from soil temperatures at a depth of $5 \mathrm{~cm}$ from 15 October through 15 May were less than 108 CDD for $20 \%$ of location-year combinations examined. These findings suggested that soil temperatures conducive for the survival of asexual propagules of $P$. infestans in infested seed may occur in Wisconsin.

Table 5. Analysis of variance table for the linear model describing the effect of cold exposure and clonal lineage on vigor of the surviving Phytophthora infestans individuals isolated from tomato seed

\begin{tabular}{lrcccc}
\hline Model terms $^{\mathbf{a}}$ & DF $^{\mathbf{b}}$ & $\mathbf{S S}^{\mathbf{c}}$ & $\mathbf{M S}^{\mathbf{d}}$ & $\boldsymbol{F}$ value $^{\mathbf{e}}$ & $\operatorname{Pr}(>\boldsymbol{F})^{\mathbf{f}}$ \\
\hline CL & 2 & 1.14 & 0.19 & 31.3 & $<0.0001$ \\
Log $($ CDD $)$ & 1 & 0.23 & 0.23 & 12.6 & 0.0004 \\
Exp & 2 & 0.11 & 0.06 & 3.01 & 0.0506 \\
CL $\times \log (\mathrm{CDD})$ & 2 & 0.16 & 0.08 & 4.3 & 0.01404 \\
CL $\times$ Exp & 4 & 0.12 & 0.03 & 1.7 & 0.1516 \\
Log (CDD) $\times$ Exp & 2 & 0.04 & 0.02 & 1.1 & 0.3230 \\
CL $\times \log (C D D) \times$ Exp & 4 & 0.04 & 0.01 & 0.59 & 0.6715 \\
Residuals & 307 & 5.61 & 0.02 & $\ldots$ & $\ldots$ \\
\hline
\end{tabular}

${ }^{a} \mathrm{CL}$ refers to isolates of a $P$. infestans clonal lineage, CDD refers to cooling degree-days base $19^{\circ} \mathrm{C}$, and Exp refers to experimental replication. $R^{2}$ (adjusted) $=0.21$, Overall $F$ statistic $=5.96, \mathrm{DF}=17,307$, and $P<0.0001$.

b Degrees of freedom associated with each model term.

c Sum of squares explained by each model term.

d Mean square (i.e., $\mathrm{MS}=\mathrm{SS} / \mathrm{DF}$ ).

e $F$ value $=\mathrm{MS}_{\text {model }} / \mathrm{MS}_{\text {residual }}$.

${ }^{\mathrm{f}} \operatorname{Pr}(>F)=$ the probability of obtaining an $F$ value more extreme than the $F$ value.

Table 4. Average length of time in days (standard error) and proportion of Phytophthora infestans-infested seed expected to contain living $P$. infestans for the US-22, US-23, and US-24 isolates at three temperatures (Temp), as predicted by the cooling degree-day (CDD) model

\begin{tabular}{|c|c|c|c|c|}
\hline \multirow[b]{2}{*}{$\operatorname{Temp}\left({ }^{\circ} \mathrm{C}\right)$} & \multirow[b]{2}{*}{$\operatorname{Pr}(\text { alive })^{\mathbf{a}}$} & \multicolumn{2}{|c|}{ Dose } & \multirow[b]{2}{*}{ Number of days } \\
\hline & & $\log _{e}(C D D) \pm S E^{b}$ & $\mathrm{CDD}\left({ }^{\circ} \mathrm{C}\right)$ & \\
\hline \multirow[t]{3}{*}{0} & 0.50 & $2.75(0.04)$ & $14.0-15.3$ & $14.0-15.3$ \\
\hline & 0.25 & $3.47(0.05)$ & $29.6-32.8$ & $29.6-32.8$ \\
\hline & 0.05 & $4.68(0.09)$ & $98.5-116.9$ & $98.5-116.9$ \\
\hline \multirow[t]{3}{*}{-3} & 0.50 & $2.75(0.04)$ & $14.0-15.3$ & $3.5-3.8$ \\
\hline & 0.25 & $3.47(0.05)$ & $29.6-32.8$ & $7.4-8.2$ \\
\hline & 0.05 & $4.68(0.09)$ & $98.5-116.9$ & $24.6-29.2$ \\
\hline \multirow[t]{3}{*}{-5} & 0.50 & $2.75(0.04)$ & $14.0-15.3$ & $2.3-2.6$ \\
\hline & 0.25 & $3.47(0.05)$ & $29.6-32.8$ & $4.9-5.5$ \\
\hline & 0.05 & $4.68(0.09)$ & $98.5-116.9$ & $16.4-19.5$ \\
\hline
\end{tabular}

${ }^{a}$ Cold exposure that would result in survival of 50,25, and 5\% of the population of $P$. infestans in infected tomato seed (or mortality of 50,75, and 95\% of the population).

b SE refers to standard error. 
New CL of $P$. infestans have been identified in the United States since the 1980 s, despite a lack of evidence for sexual recombination or spontaneous mutation. US-1 is believed to have been the first and predominant lineage in the United States up until the late 1980s, when the US-8 CL effectively displaced it in just a few years (Goodwin et al. 1998; Marshall-Farrar et al. 1998). Newer lineages have been identified and successively named but their occurrence generally has been ephemeral and their presence often limited to a particular geographic region (Ristaino 2010; Seidl and Gevens 2013; Seidl Johnson and Gevens 2014). In 2009, the US-22 CL quickly spread across much of the United States (Danies et al. 2013; Gevens et al. 2010, 2013a,b; Hu et al. 2012). In the following 4 years, US-23 and US-24 also were identified, with US-23 gaining predominance in most national potato and tomato late blight epidemics (Danies et al. 2013; Gevens et al. 2010, 2013a,b). The

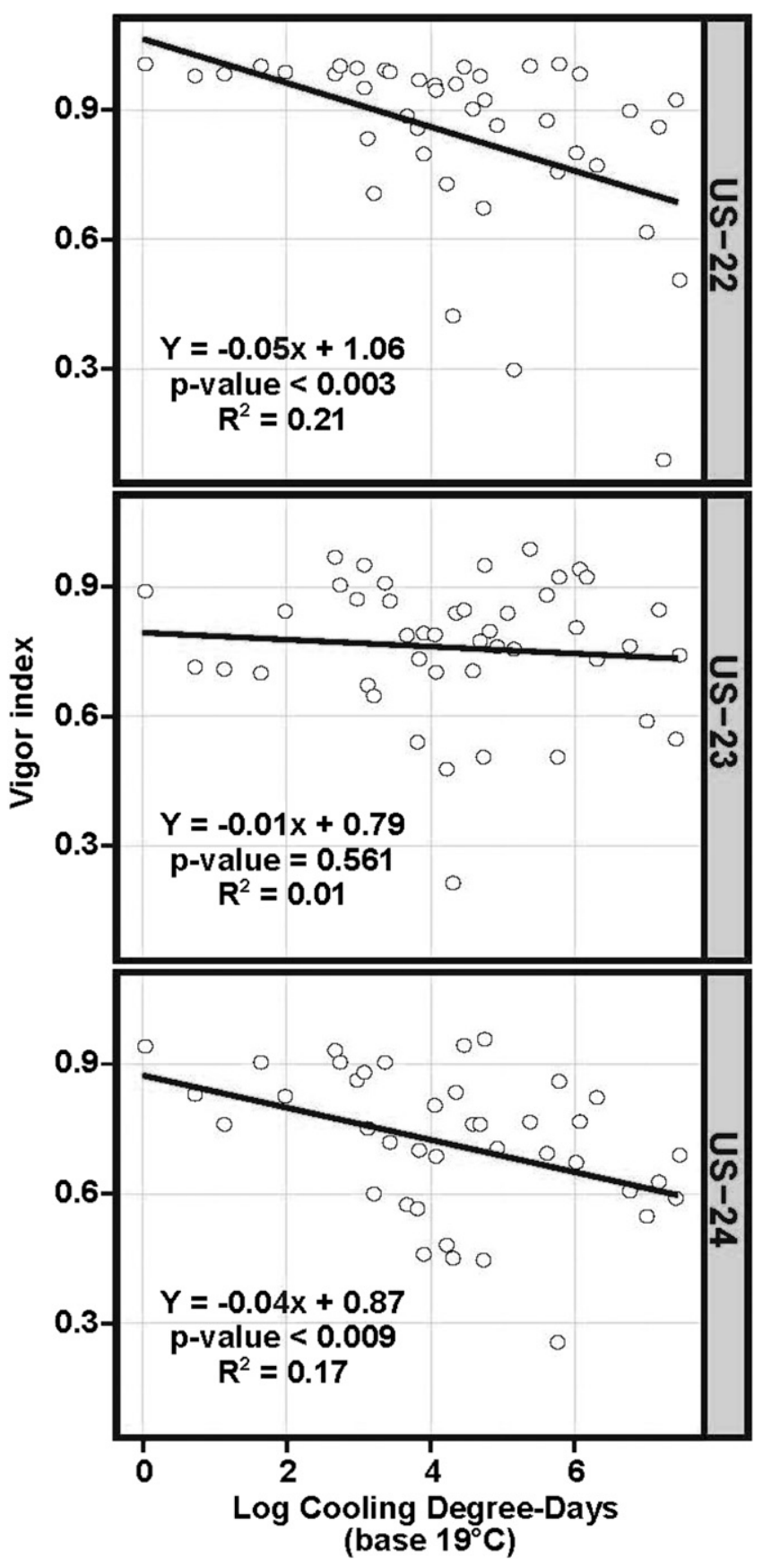

Fig. 3. Vigor of surviving Phytophthora infestans isolated from infested tomato seed following exposure to cold temperatures. Isolates of the A, US-22; B, US-23; and C, US-24 clonal lineages are represented. displacement of CL since the 1980s suggests that the displacing lineages may have enhanced fitness over the displaced. Changes that can increase the probability that a CL will successfully survive, reproduce, and cause disease (Antonovics and Alexander 1989; deBruyn 1926) may include the ability to produce more sporangia (Hu et al. 2012; Van den Bosch and Kiessel 2007), infect a wider range of hosts (Golas et al. 2010; Grönberg et al. 2012; Vartanian and Endo 1985a; Wisconsin Department of Agriculture, Trade and Consumer Protection 2012), have greater rates of direct or indirect germination (Hu et al. 2012), or survive at broader temperature ranges (Goodwin et al.

Table 6. Calculated cooling degree-day accumulations using a base temperature of $1^{\circ} \mathrm{C}$ for temperatures measured at soil depths of 5 and $10 \mathrm{~cm}$ and in Antigo, Arlington, Hancock, and Spring Green, WI

\begin{tabular}{|c|c|c|c|c|c|c|c|c|}
\hline \multirow[b]{2}{*}{ Year } & \multicolumn{2}{|c|}{ Antigo } & \multicolumn{2}{|c|}{ Arlington } & \multicolumn{2}{|c|}{ Hancock } & \multicolumn{2}{|c|}{ Spring Green } \\
\hline & $5 \mathrm{~cm}$ & $10 \mathrm{~cm}$ & $5 \mathrm{~cm}$ & $10 \mathrm{~cm}$ & $5 \mathrm{~cm}$ & $10 \mathrm{~cm}$ & $5 \mathrm{~cm}$ & $10 \mathrm{~cm}$ \\
\hline 1987 & $\ldots$ & $\ldots$ & 58 & 83 & 0 & 0 & $\ldots$ & $\ldots$ \\
\hline 1988 & 15 & 7 & 266 & 268 & 40 & 60 & $\ldots$ & $\ldots$ \\
\hline 1989 & 264 & 191 & 153 & 169 & 490 & 568 & 324 & 284 \\
\hline 1990 & 93 & 18 & 4 & 13 & 35 & 90 & 156 & 157 \\
\hline 1991 & 49 & 10 & 96 & 103 & 264 & 432 & 180 & 177 \\
\hline 1992 & 9 & 0 & 44 & 158 & 310 & 614 & 366 & 379 \\
\hline 1993 & 6 & 124 & 5 & 94 & 355 & 605 & 222 & 235 \\
\hline 1994 & 43 & 137 & 109 & 262 & 391 & 287 & 229 & 289 \\
\hline 1995 & 452 & 387 & 2 & 94 & 235 & 125 & 350 & 436 \\
\hline 1996 & 239 & 201 & 232 & 192 & 56 & 0 & 326 & 440 \\
\hline 1997 & 222 & 181 & 100 & 61 & 209 & 188 & 128 & 221 \\
\hline 1998 & $\ldots$ & $\ldots$ & 168 & 142 & 121 & 107 & $\ldots$ & $\cdots$ \\
\hline 1999 & $\cdots$ & $\ldots$ & 71 & 60 & 226 & 197 & $\ldots$ & $\ldots$ \\
\hline 2000 & $\ldots$ & $\ldots$ & 170 & 135 & 49 & 4 & $\ldots$ & $\ldots$ \\
\hline 2001 & $\ldots$ & $\ldots$ & 128 & 99 & 76 & 72 & 143 & 295 \\
\hline 2002 & $\ldots$ & $\ldots$ & 510 & 419 & 479 & 444 & 395 & 632 \\
\hline 2003 & $\ldots$ & $\ldots$ & 272 & 212 & 222 & 209 & 243 & 512 \\
\hline 2004 & $\ldots$ & $\ldots$ & 251 & 224 & 333 & 322 & 120 & 570 \\
\hline 2005 & $\ldots$ & $\ldots$ & 92 & 94 & 199 & 186 & 94 & 82 \\
\hline 2006 & $\ldots$ & $\ldots$ & 224 & 211 & 236 & 209 & 127 & 84 \\
\hline 2007 & $\ldots$ & $\ldots$ & 161 & 80 & 109 & 85 & 74 & 23 \\
\hline 2008 & $\ldots$ & $\ldots$ & 317 & 192 & 216 & 196 & 120 & 45 \\
\hline 2009 & $\ldots$ & $\ldots$ & 127 & 20 & 149 & 130 & 108 & 50 \\
\hline 2010 & $\ldots$ & $\ldots$ & 203 & 165 & 207 & 186 & 231 & 121 \\
\hline 2011 & $\ldots$ & $\ldots$ & 83 & 81 & 206 & 182 & 113 & 46 \\
\hline 2012 & $\ldots$ & $\ldots$ & 147 & 98 & 207 & 183 & $\ldots$ & $\ldots$ \\
\hline 2013 & $\ldots$ & $\ldots$ & 133 & 84 & 108 & 98 & $\ldots$ & $\ldots$ \\
\hline
\end{tabular}

Table 7. Percentage of years in which 5, 25, and 50\% of Phytophthora infestans in infested tomato seed would likely survive overwinter based on cooling degree-day (CDD) accumulations using soil temperatures at depths of 5 and $10 \mathrm{~cm}$ at four Wisconsin locations

\begin{tabular}{llcccc}
\hline & & & \multicolumn{3}{c}{ Pr (alive) } \\
\cline { 4 - 6 } Soil depth & Location $^{\mathbf{b}}$ & CDD (SD) & $\mathbf{0 . 0 5}$ & $\mathbf{0 . 2 5}$ & $\mathbf{0 . 5 0}$ \\
\hline $5 \mathrm{~cm}$ & A & $139(149)$ & 60 & 30 & 30 \\
& B & $152(110)$ & 37 & 11 & 11 \\
& C & $204(130)$ & 22 & 4 & 4 \\
& D & $184(113)$ & 18 & 9 & 9 \\
$10 \mathrm{~cm}$ & Average & $\ldots$ & 34 & 14 & 14 \\
& A & $126(123)$ & 40 & 40 & 30 \\
& B & $141(88)$ & 51 & 7 & 4 \\
& C & $214(177)$ & 30 & 11 & 11 \\
& D & $231(194)$ & 36 & 13 & 9 \\
& Average & $\ldots$ & 39 & 18 & 14
\end{tabular}

${ }^{\text {a }} \operatorname{Pr}$ (alive) is the proportion $(0.50,0.25$, or 0.05$)$ of $P$. infestans individuals in a population of $P$. infestans-infested tomato seed expected to survive.

b $\mathrm{A}=\operatorname{Antigo}\left(N_{\text {years }}=10\right), \mathrm{B}=\operatorname{Arlington}\left(N_{\text {years }}=27\right), \mathrm{C}=\operatorname{Hancock}\left(N_{\text {years }}=\right.$ $27)$, and $\mathrm{D}=$ Spring Green $\left(N_{\text {years }}=22\right)$.

c Average $\mathrm{CDD} 1{ }^{\circ} \mathrm{C}$. SD refers to standard deviation. 
1998; Montarry et al. 2007; Smart and Fry 2001; Van den Bosch and Kiessel 2007).

In this work, an isolate representing each of the three lineages survived on tomato seed at low temperatures for longer periods of time than has been previously reported (Dandurand et al. 2006; deBruyn 1926; Kirk 2003b). This difference could be due to the medium on which the survival assays were conducted. Autoclaved tomato seed were used in this study but previous studies have not used seed as a medium for a survival assay. The results may also indicate that new lineages are better able to survive temperatures at or below freezing than previously common lineages. In general, the $P$. infestans isolates representing the US-22, US-23, and US-24 CL performed similarly in the survival assays. However, small differences in survival at low temperatures were observed among the three CL (Danies et al. 2013; Hu et al. 2012; Kalischuk et al. 2012; Seidl and Gevens 2013). Specifically, US-24 was predicted to survive for the shortest duration (8 days) at $-3^{\circ} \mathrm{C}$ while US- 23 was predicted to survive over twice as long (17 days) at that temperature. It is not known whether the differences in survival among these isolates representing the different CL would be biologically important (or important in the field).

The ability of $P$. infestans to cause late blight on tomato seedlings from infected or infested seed has been demonstrated previously. For example, Vartanian and Endo (1985b) showed a 34\% rate of disease on tomato seedlings arising from infected seed on sterile soil. Even on nonsterile field soil, $18 \%$ of seedlings arising from late-blightinfected seed showed signs and symptoms of late blight. Additionally, in a field setting, clusters of tomato seedlings infected with $P$. infestans at their crown have been observed (Vartanian and Endo 1985a). This finding suggested that the seedlings arose from an infected tomato fruit or seed that survived over the winter from the previous growing season; $P$. infestans infection from aerial inoculum is more likely to occur in the plant canopy and less likely to occur at the crown of the plant (Vartanian and Endo 1985a). Given that infected seedlings can arise from infested or infected seed containing viable $P$. infestans, it is reasonable to consider that volunteer tomato seedlings could provide a primary inoculum source for initiating late blight epidemics, even in regions with freezing winters.

The possibility that the asexual life stage of the new CL of $P$. infestans may be able to survive over the winter in the northern United States on tomato seed has important implications for tomato and potato late blight management in these areas. In Wisconsin, potato cull piles are carefully managed and even regulated because of their documented ability to be a source of inoculum for late blight, even in northern regions with freezing winters (Bonde and Schultz 1943; Kirk 2003a,b; Kirk et al. 2001; Wisconsin Department of Agriculture, Trade and Consumer Protection 2012). Tomato plants are known to freeze overwinter, destroying all of the living plant material needed for $P$. infestans to survive. However, tomato seed is known to survive over the winter and, unlike potato cull piles, volunteer tomato seedlings are not currently regulated in Wisconsin, even though the plants can produce sporangia that may be a source of inoculum for both tomato and potato production fields. Tomato growers should be aware of the potential for $P$. infestans to survive over the winter on or in tomato seed of infected tomato fruit that have been covered by soil or snow, and be prepared to manage volunteer plants in the subsequent spring.

Exposure to cold also affected the vigor of some of the surviving $P$. infestans isolates. For example, the vigor of the US-22 and US-24 isolates decreased as a function of cold exposure. This observed decrease of vigor was primarily due to a delayed initiation of $P$. infestans growth from the tomato seed after the cold treatment. Occasionally, $P$. infestans would not grow out of a tomato seed until the 3-week evaluation point of the experiment. In part, this delay may explain the phenology of late blight and why it is considered to be a mid- to late-season disease. If the observed growth rates of sterile media were extrapolated to tomato seedlings in the field, it would likely be a month or longer before late blight lesions would develop enough to become noticeable on a field scale. For the isolate representing the US-23 CL, vigor of the surviving individuals was not affected by exposure to cold. The US-23 isolate effectively had a head start in growth compared with the US-22 and US-24 isolates, which might also explain, in part, why the US-23 CL has become predominant in the Wisconsin environment (Seidl and Gevens 2013).

Our initial data analysis considered calendar time as the correct scale for describing survival as a function of cold exposure; survival varied depending on the time spent at a given temperature. However, our second analysis described the survival of $P$. infestans as a function of CDD and considered the existence of a thermal time scale that relates to the survival of $P$. infestans. The calculation of CDD is an integration of temperature with respect to exposure time. It combines temperature and time into a single metric that represents exposure to cold temperatures. CDD can be calculated for time periods with varying temperatures and, assuming survival only depends on temperature, is a useful concept for extending constant temperature laboratory studies to the field. The CDD model was used to predict whether soil temperature conditions existed in Wisconsin that would be conducive for overwinter survival of $P$. infestans. In total, from CDD calculated from $15 \mathrm{Oc}-$ tober through 1 May, the model predicted 5\% survival of $P$. infestans at 35 and $39 \%$ of the 86 location-year combinations at 5 - and $10-\mathrm{cm}$ soil depths, respectively. In roughly $14 \%$ of the winters examined, likely due to warmer winter air temperatures or deeper snow cover, the degree-day model predicted that $50 \%$ of $P$. infestans individuals in a population of infected seed would survive at both soil depths. These data suggest that, despite significant annual and site-specific variation of factors that influence soil temperature, (temperature) conditions that would allow $P$. infestans to survive over the winter in wet tomato seed likely occur at northern U.S. latitudes. However, survival of $P$. infestans over the winter is not typically observed in Wisconsin, suggesting that temperature is not the only factor determining survival; freeze-thaw cycles, desiccation, or antagonistic interactions with other soil microbes may greatly influence the survival of $P$. infestans over the winter.

Many factors can influence soil temperature and affect the overwintering ability of $P$. infestans in its asexual life stage in northern latitudes. For example, soil temperatures at different locations may fluctuate due to differences in air temperature and soil type, and moisture content can further influence soil temperature (Al-Kayssi et al. 1990). Soil microclimates can also exist at relatively small geographic scales. Backyard garden plots in cities often are more sheltered and warmer than garden plots in rural areas, temperatures in compost piles may be warmer due to microbial activity (Martin et al. 1992), and abundant snowfall in certain years or localized snow drifting may insulate the ground, preventing lower soil temperatures. Therefore, generalizing results from one or a few locations may lead to inappropriate conclusions about the ability of $P$. infestans to survive over the winter at all locations. However, soil temperature data that have been collected over multiple years and locations can help determine the longterm frequency in which $P$. infestans survival over the winter season is likely to occur. Long-term monitoring of soil temperature in northern climates will continue to be important as regions that may have normally had soil temperatures cold enough to eliminate $P$. infestans may become warmer due to climate change (Anderegg et al. 2010; Widrlechner et al. 2012). Further in situ investigations are necessary to determine the viability and transmissibility from seed to seedling of $P$. infestans after its survival over the winter season, given that soil temperatures can fluctuate greatly in the northern latitudes.

\section{Acknowledgments}

This work was supported, in part, by Hatch Formula Funds granted to A. J. Gevens at the University of Wisconsin-Madison for the graduate research funding of A. C. Seidl Johnson, and a Wisconsin Potato Industry Board-Wisconsin Distinguished Graduate Fellowship awarded to A. C. Seidl Johnson. We thank S. Jordan, L. Thomas, A. Mitchell, and S. Donovan for technical assistance in the University of Wisconsin Potato and Vegetable Pathology Laboratory.

\section{Literature Cited}

Al-Kayssi, A. W., Al-Karaghouli, A. A., Hasson, A. M., and Beker, S. A. 1990 Influence of soil moisture content on soil temperature and heat storage under greenhouse conditions. J. Agric. Eng. Res. 45:241-252.

Anderegg, W. R. L., Prall, J. W., Harold, J., and Schneider, S. H. 2010. Expert credibility in climate change. Proc. Natl. Acad. Sci. USA 107: 12107-12109.

Antonovics, J., and Alexander, H. M. 1989. The concept of fitness in plant-fungal pathogen systems. Pages 185-214 in: Plant Disease Epidemiology, Vol. 2. K. J Leonard and W. E. Fry, eds. McGraw-Hill, New York. 
Bonde, R., and Schultz, E. S. 1943. Potato cull piles as a source of late blight infection. Am. Potato J. 20:112-118.

Campbell, G. S., and Norman, J. M. 1998. An Introduction to Environmental Biophysics, 2nd ed. Springer Science+Business Media, Inc., New York.

Caten, C. E., and Jinks, J. L. 1968. Spontaneous variability of a single isolate of Phytophthora infestans. I. Cultural variation. Can. J. Bot. 46:329-348.

Dandurand, L. M., Knudsen, G. R., and Eberlein, C. V. 2006. Susceptibility of five nightshade (Solanum) species to Phytophthora infestans. Am. J. Potato Res. 83:205-210.

Danies, G., Small, I. M., Myers, K., Childers, R. A., and Fry, W. E. 2013. Phenotypic characterization of recent clonal lineages of Phytophthora infestans in the United States. Plant Dis. 97:873-881.

deBruyn, H. L. G. 1926. The overwintering of Phytophthora infestans (Mont.) de Bary. Phytopathology 16:121-138.

Fry, W. E. 2007. The canon of potato science: Late blight and early blight. Potato Res. 50:243-245.

Fry, W. E. 2008. Phytophthora infestans: The plant (and $R$ gene) destroyer. Mol. Plant Pathol. 9:385-402.

Gavino, P. D., Smart, C. D., Sandrock, R. W., Miller, J. S., Hamm, P. B., Lee, T. Y., Davis, R. M., and Fry, W. E. 2000. Implications of sexual reproduction for Phytophthora infestans in the United States: Generation of an aggressive lineage. Plant Dis. 84:731-735.

Gevens, A. J., and Seidl, A. C. 2013a. First report of late blight caused by Phytophthora infestans clonal lineage US-23 on tomato and potato in Wisconsin, United States. Plant Dis. 97:839.

Gevens, A. J., and Seidl, A. C. 2013b. First report of late blight caused by Phytophthora infestans clonal lineage US-24 on potato (Solanum tuberosum) in Wisconsin. Plant Dis. 97:152.

Gevens, A. J., Seidl, A. C., and Hudelson, B. 2010. Page 2 in: Late Blight. University of Wisconsin Garden Facts. University of Wisconsin Extension, Madison.

Gigot, J. A., Gundersen, B., and Inglis, D. A. 2009. Colonization and sporulation of Phytophthora infestans on volunteer potatoes under western Washington conditions. Am. J. Potato Res. 86:1-14.

Golas, T. M., van der Weerden, G. M., van den Berg, R. G., Mariani, C., and Allefs, J. J. H. M. 2010. Role of Solanum dulcamara L. in potato late blight epidemiology. Potato Res. 53:69-81.

Goodwin, S. B., Smart, C. D., Sandrock, R. W., Deahl, K. L., Punja, Z. K., and Fry, W. E. 1998. Genetic change within populations of Phytophthora infestans in the United States and Canada during 1994 to 1996: Role of migration and recombination. Phytopathology 88:939-949.

Goth, R. W. 1981. An efficient technique for prolonged storage of Phytophthora infestans. Am. Potato J. 58:257-260.

Grönberg, L., Andersson, B., and Yuen, J. E. 2012. Can weed hosts increase aggressiveness of Phytophthora infestans on potato? Phytopathology 102:429-433.

Guenthner, J. F., Michael, K. C., and Nolte, P. 2001. The economic impact of potato late blight on U.S. growers. Potato Res. 44:121-125.

Hodgson, W. A., and Grainger, P. N. 1964. Culture of Phytophthora infestans on artificial media prepared from rye seeds. Can. J. Plant Sci. 44:583.

Hu, C.-H., Perez, F. G., Donahoo, R. S., McLeod, A., Myers, K., Ivors, K., Secor, G., Roberts, P. D., Deahl, K. L., Fry, W. E., and Ristaino, J. B. 2012. Recent genotypes of Phytophthora infestans in the eastern United States reveal clonal populations and reappearance of mefenoxam sensitivity. Plant Dis. 96: 1323-1330.

Johnson, D. A., and Cummings, T. F. 2013. A plant stem inoculation assay for assessing transmission of Phytopthora infestans from potato seed tubers to emerged shoots. Plant Dis. 97:183-188.

Kalischuk, M., Al-Mughrabi, K. I., Peters, R. D., Howard, R. J., Platt, H. W., and Kawchuk, L. M. 2012. Genetic composition of Phytophthora infestans in Canada reveals migration and increased diversity. Plant Dis. 96:1729-1735.

Kirk, W. W. 2003a. Thermal properties of overwintered piles of cull potatoes. Am. J. Potato Res. 80:145-149.

Kirk, W. W. 2003b. Tolerance of mycelium of different genotypes of Phytophthora infestans to freezing temperatures for extended periods. Phytopathology 93:1400-1406.
Kirk, W. W., Niemira, B. A., and Stein, J. M. 2001. Influence of storage temperature on rate of potato tuber tissue infection caused by differen biotypes of Phytophthora infestans (Mont.) de Bary estimated by digital image analysis. Potato Res. 44:87-96.

Kutner, M. H., Nachtsheim, C. J., and Neter, J. 2004. Applied Linear Regression Models, 4th ed. The McGraw-Hill Companies, Inc. New York.

Lambert, D. H., Currier, A. I., and Olanya, M. O. 1998. Transmission of Phytophthora infestans in cut potato seed. Am. J. Potato Res. 75:257-263.

Lamour, K. H., and Hausbeck, M. K. 2001. Investigating the spaciotemporal genetic structure of Phytophthora capsici in Michigan. Phytopathology 91 973-980.

Marshall-Farrar, K., McGrath, M., James, R., and Stevenson, W. 1998 Characterization of Phytophthora infestans in Wisconsin from 1993 to 1995. Plant Dis. 82:434-436.

Martin, D. L., Minnich, J., and Gershuny, G. 1992. The Rodale Book of Composting: Easy Methods for Every Gardener. Rhodale Press, Emmaus, PA

Mizubuti, E. S. G., and Fry, W. E. 1998. Temperature effects on developmenta stages of isolates from three clonal lineages of Phytophthora infestans. Phytopathology 88:837-843.

Montarry, J., Corbiere, R., and Andrivon, D. 2007. Is there a trade-off between aggressiveness and overwinter survival in Phytophthora infestans? Funct Ecol. 21:603-610

R Core Team. 2014. R: A language and environment for statistical computing. $\mathrm{R}$ Foundation for Statistical Computing, Vienna. Online publication. http://www R-project.org/

Ristaino, J. B. 2010. The 2009 potato and tomato late blight epidemics: Genealogical history, multiple sources and migration events. (Abstr.) Phytopathology 100:S161.

Seidl, A. C., and Gevens, A. J. 2013. Characterization and distribution of three new clonal lineages of Phytophthora infestans causing late blight in Wisconsin from 2009 to 2012. Am. J. Potato Res. 90:551-560.

Seidl Johnson, A. C., and Gevens, A. J. 2014. Investigating the host range of the US-22, US-23, and US-24 clonal lineages of Phytophthora infestans on solanaceous cultivated plants and weeds. Plant Dis. 98:754-760.

Smart, C. D., and Fry, W. E. 2001. Invasions by the late blight pathogen: Renewed sex and enhanced fitness. Biol. Invasions 3:235-243.

Stevenson, W. R., Loria, R., Franc, G. D., and Weingartner, D. P. 2001 Compendium of Potato Diseases. American Phytopathological Society Press, St. Paul, MN.

Thurston, H. D. 1957. The culture of Phytophthora infestans. (Abstr.) Phytopathology 47:186.

Van den Bosch, G. B. M., and Kiessel, G. J. T. 2007. Epidemic fitness of Phytophthora infestans in foliage and tubers during growing season and harvest. PPO Spec. Rep. 12:49-54.

Vartanian, V. G., and Endo, R. M. 1985a. Overwintering hosts, compatibility types, and races of Phytophthora infestans on tomato in southern California. Plant Dis. 69:516-519.

Vartanian, V. G., and Endo, R. M. 1985b. Survival of Phytophthora infestans in seeds extracted from infected tomato fruits. Phytopathology 75:375-378.

Venables, W. N., and Ripley, B. D. 2002. Modern Applied Statistics with S, 4th ed Springer Publishing Company, New York.

Waterhouse, G. M. 1963. Key to the Species of Phytophthora de Bary. Mycol. Pap 92. Commonwealth Mycological Institute, Kew, Surrey, UK

Widrlechner, M. P., Daly, C., Keller, M., and Kaplan, K. 2012. Horticultural applications of a newly revised USDA plant hardiness zone map. HortTechnology 22:6-19.

Wisconsin Department of Agriculture, Trade and Consumer Protection. 2012. Diseases: Late blight on tomatoes and potatoes. Online publication. http://datcp. wi.gov/Plants/Diseases/Late_Blight/index.aspx

Wustman, R. 2007. The canon of potato science: Storage diseases and pests. Potato Res. 50:289-292.

Zwankhuizen, M. J., Govers, F., and Zadoks, J. C. 1998. Development of potato late blight epidemics: Disease foci, disease gradients, and infection sources. Phytopathology 88:754-763. 